\title{
Online Shopping: A Potential of Herding Behavior Symptom?
}

\author{
Noor Azuan Hashim (Corresponding author) \\ Faculty Economics and Management, Universiti Kebangsaan Malaysia \\ 43600 UKM Bangi, Selangor, Malaysia \\ E-mail: azuan@ukm.edu.my
}

\begin{abstract}
Hawati Janor
Faculty Economics and Management, Universiti Kebangsaan Malaysia 43600 UKM Bangi, Selangor, Malaysia

E-mail: hawati@ukm.edu.my

Farhana Sidek

Faculty Economics and Management, Universiti Kebangsaan Malaysia 43600 UKM Bangi, Selangor, Malaysia

E-mail: sfarhana@ukm.edu.my
\end{abstract}

\author{
Shifa Mohd Nor \\ Faculty Economics and Management, Universiti Kebangsaan Malaysia \\ 43600 UKM Bangi, Selangor, Malaysia \\ E-mail: shifa@ukm.edu.my
}

Received: Dec. 7, $2018 \quad$ Accepted: Dec. 28, $2018 \quad$ Published: Dec. 30, 2018

doi:10.5296/bmh.v6i2.14197ＵRL: http://dx.doi.org/10.5296/bmh.v6i2.14197 


\title{
Macrothink
}

\begin{abstract}
The Internet has grown tremendously in the recent and many of its applications have been used by people all over the world. On-line shopping which is a recent phenomenon in the field of e-commerce is definitely going to be the future of shopping in the world. It seems that online shopping has been one of the ways that customers shop nowadays especially to the younger generations and working people. Most of the young working people have accessed to Internet and many have started to sell and buy online. Though online shopping is quite common now, its growth in Malaysian market is still not in line with the global market. The potential growth of online shopping has triggered the idea of conducting an exploratory study on online shopping in Malaysia. A survey was carried-out with 168 part-time students who work in Klang Valley area and also currently study in UKM. In addition to the survey, 15 face-to-face interviews were carried-out with available respondents after they answer the survey. The purpose is to find out how well they understand about online shopping and what factors contribute to their online shopping behaviors. The results of study reveal that customer satisfaction, motivation and influence from other buyers are among the critical factors for customers to shop online. Respondents since to mimic other customers in buying online. The results of the study could be further used by the researchers and practitioners for conducting future studies in the similar area.
\end{abstract}

Keywords: internet, on-line shopping, customer satisfaction, motivation, customer influence 


\section{Introduction}

Since the Internet started to be used commercially in the 1990s (Zwass, 1996), electronic commerce (e-commerce) has emerged as a significant topic in the literature (Hashim et al., 2016). Many authors insist e-commerce has a significant and positive impact on businesses everywhere (Hashim et al., 2013). Policy makers as well as practitioners seem certain that e-commerce conveys benefits, insisting that companies which eschew e-commerce will be left behind in the global marketplace (Daniel et al., 2003; Hashim, 2017).

Online shopping, process of buying goods and services, is a form of electronic commerce which allows consumers to directly buy goods or services from a seller over the Internet using an Internet browser. It is a shopping trends nowadays where online shoppers do not only buy in big online stores but also in hundreds of thousands of stores shipping products all over the world. Online buyers can visit web stores as they sit in front of the computer from the comfort of their homes or shop. They can buy anytime and anywhere online as long as they are connected to the Internet (Daniel et al., 2003) either using "search" features to find specific models, brands or items or by clicking the advertisement shown online. They can purchase just about anything from companies that provide their products online. Online sellers, on the other hand, just need to seek what to sell to people who surf the Internet and to study the trends on online shopping. Books, clothing, household appliances, toys, hardware, software, and health insurance are just some of the thousands of products that have been advertised from an online store.

Online shopping has becoming popular, particularly to younger generations who have now accessed to many kinds of technologies (Bianchi and Andrews, 2012). Part of the reasons is because of the convenience and flexibility (Harn et al., 2006). In online shopping, buyer do not need to go to a brick-and-mortar store, drive to there, find a parking place, and walk throughout the store until she locates the products she needs and also queue at the cash register. They just need to be online and some sort of online payment systems. Despite these conveniences, not everyone chooses to purchase items and services online. Some are reluctant to shop online because they think it is not safe, the security is poor and in facts some think that to shop online is a waste of time. There is very limited knowledge about online shopping consumer behavior because it is a complicated socio-technical phenomenon and involves too many factors (Bianchi \& Andrews, 2012).

Thus, the goal of this study is to provide a clearer understanding of this socio-technical phenomenon by investigating the motives and insights of online shopping behaviour and the factors affecting this behaviour, particularly among university students, i.e. the research questions for this study is: "To what extent do student buy online and what are the most influencing factors of online buying?" This paper is organized as follows. Section 1 presents the introduction of the paper, follows by the literature review in Section 2. Next section demonstrates the conceptual framework of this study, follows by the methodology of the study. Section 5 presents the findings and discussion of the study. Finally, the last section displays the conclusion and recommendations of the study. 


\section{Literature Review}

\subsection{E-commerce}

E-commerce has been described in the large body of literature that has emerged since the explosion of Internet technology. Empirical research, especially at the technological innovator level, suggests that e-commerce has a significant and positive impact on businesses everywhere (Chuang et al., 2007; Hashim et al., 2013). E-commerce, a process buying and selling over the Internet, is said to replace the traditional way that people do business. In fact, it has becoming an important ways of doing business among people nowadays.

The growth of global ecommerce is tremendous. In 2017 it reached around \$2.3 trillion and is expected to hit $\$ 4.5$ trillion in 2021 (Statista, 2018). In the US alone, ecommerce represents almost 10 percent of retail sales - a figure that is growing by nearly 15 percent each year (Statista, 2018). In Malaysia, although e-commerce is in quite a recent phenomenon, the sector is one of the fastest growing and most attractive industries (Chew, 2018). The latest estimate by Statista (2018) revealed that the e-commerce platform has garnered revenue of RM4.2 billion by the end of 2017. Part of the reasons is because there were 15.1 million active users in Malaysia, which is 47.9 per cent of the Malaysian population (Statista, 2018). With the introduction of more affordable Internet and broadband plans each year, the number of Internet users is expected to continually rise year on year. The e-commerce industry is expected to generate RM9.8 billion in revenue by 2022 (Statista, 2018). The main factor that drove e-commerce's rise in popularity was also due to the existence of attractive products and services that was once not available through conventional businesses (Yin et al., 2016).

\subsection{Online Shopping}

The growth of the Internet and e-commerce as a shopping channel has developed since 1994 (Zwass, 1995). Now days, online shopping have become very popular because of vast availability of Internet. It is a process of buying or selling products with the help of computerized business transactions electronically using the Internet (Hashim et al., 2013). Online shopping is different from brick-and-mortar shopping in many aspects. In traditional shopping, ones has to go to a store or shop, get into it, slowly walking from rack to rack, checking out the display and finally go to the check-out counter (Shambare, 2014). There is limited variety, limited choice of buyers and buyers can buy only those products which are available in local market. Online shopping, on the other hand, allows online buyers to shop wide range of products of multiple brands in unlimited time from his/her place. It has given the ability any customers to buy anything regardless of where its location as long as they are connected to Internet. For the purpose of this study, online shopping is defined as "a shopping and buying activity performed by a consumer via computer-based interface, where the consumeres computer is connected to, and can interact with, a retailer"s digital storefront" (Yin et al., 2016).

Online shopping is a multibillion dollar growing market growing at 35 percent a year (Statista, 2018). It is not only impacted the economy but also culture and everyday routine. For example, e-commerce reviews on blogs, websites, or social platforms - to get personal insights, 
perspective, and recommendations has led the way in generating retail lift from what current users think about brands they may want to buy (Debroff, 2017). As a result, there is an increasingly in consumer saying "no" to brand loyalty (Debroff, 2017). Consumers not only look a new brand in mind but also scan the shelves for the best price (Bourlakis et al., 2008). The World Wide Web allows consumers to see different goods from different countries. Now shopping is no longer done in a limited area but can be done, nationwide and even worldwide (Bourlakis et al., 2008).

Despite the advantages of online shopping, there are some drawbacks. Although many businesses are prospering, many non-Internet based businesses are suffering a great financial lost (Hashim et al., 2013), particularly businesses that act as intermediaries. The travel ticketing agent, for example, has been impacted quite tremendously. Most people now but ticket online rather than use the travel agent. More than twenty five percent of all travel is now booked online in the US, Western Europe and Asia Pacific, and more than half a trillion dollars in global travel sales is still waiting to be booked online (Crnojevac et al., 2010). In the same vein, many other businesses such as the movie and recording industries suffered as people can download movies and music at a cheaper price. In addition, online shoppers could also underwent shopping addicted because shops are available at any time. Thus, much of consumers' time is wasted on searching what they wanted.

\subsection{Online Shopping Behaviors}

Study on UK consumer shopping behavior by Criteo (2016) reveal that $2 / 3$ of UK shoppers browse online once a month or more and $1 / 3$ of online purchases are impulse buys. They also found that more than $50 \%$ bought via mobile device and more that $75 \%$ online shoppers bought baby care products (Criteo, 2016). This study also found that shoppers browse multiple sites before they finally make decision to buy on a particular site. This is because they want more product information, want a better selection, and also what to compare shipping options (Criteo, 2016). In Taiwan, Wu and Tsai (2017) found that there are two types of consumers' behavior. Those in "high-frequency online shopping group", are more affected by the satisfactory website characteristics of an online shopping website and those of "low-frequency online shopping group are found to shop online only if the online shopping website is rich in content and good in design.

In Malaysia, online shopping is still considered as a new phenomenon especially among older generation people in the country. In their study, Madahi and Sukati (2014) found that Malaysian consumers switched Internet channel to brick-and-mortar stores because they perceived that online shopping is complex and not easy to use. Malaysian consumers still preferred the brick-and-mortar ways of shopping because it is well suited with Malaysian consumers' culture and lifestyle (Madahi and Sukati, 2014). This reluctance to change behavior and culture-bounded are among factors that prevent many Malaysian to embrace online shopping (Harn et al., 2006; Jamil and Mat, 2011). Hence, to change the Malaysian consumers' perception to e-store, online retailers need to maximize efforts in doing promotion and performing good customer services in order to raise the consumers interest in online shopping. Online retailers need to design their website in such a way to make them 
user-friendly and actively manage the social media marketing to channel traffic to their online website. To date, although there are studies conducted on online shopping behavior of consumers in Malaysia, many focus to the younger generations or different groups of people. Thus, understanding towards online shopping in Malaysia still deserves to be research.

\subsection{Students and Online Shopping}

There are strong evidences in the integration between younger generation, such as student, and online shopping (Narges et al,. 2009; Bouhnik and Deshen, 2014). Part of the reasons is because students nowadays have become so technologically and socially integrated. They were raised on social media and smart tech, and it is an integral part of their lives rather than something they have learnt to adapt to (Ryan, 2017). In their study in one of the region in India, Amit and Sailo (2013) found that customers age 18 to $33(80 \%)$ dominate the online shopping behavior. Online shopping has become an emerging trend among this age group to most of the online shoppers. On contrary, study by Marketing Dive (2018) posits that students that are in Gen Z group (borned 1994 onwards), are likely to shop in-store but turn to online just for convenience. Nearly $2 / 3$ Gen Zers (65\%) prefer being able to touch and feel products before making a purchase, and $67 \%$ use their phones in stores to research items they plan to purchase. Store design, unique merchandise, displays showing products in use and having ways to try out products are the top motivators for getting Gen $\mathrm{Z}$ shoppers into stores.

University students are one of the target markets by online retailers as most of them are owner of a connected computer or smart phone. Indeed, most of the university students have their own Internet connection lines as the service is getting cheaper nowadays. In addition, Wi-Fi is always available everywhere which make them easy to access to Internet. As they are doing their assignments, there is a big possibilities that they will browse the Internet and its applications and finally embark to online shopping. Prior studies have examined the benefits that encourage students to purchase through the Internet (Narges et al., 2009). However, studies on various factors that lead student to shop online, particularly Malaysian university students are still scarce and need to be addressed.

\subsection{Theories Related}

Online shopping is a new way to shop or buy things. In order to find a suitable framework for this study, a list of literature review on technological diffusion, perception and psychology is reviewed Chang (2005). Among them are Roger's (1995) diffusion of innovation theory (DOI), Azjen's (1991) theory of reasons action (TRA), Davis's (1989) technology acceptance model (TAM), psychology and marketing theories. DOI is mostly used in the study of innovation diffusion in organisation. TAM and TRA models focus mainly on user acceptance to analyse automation processes in the early phases of innovation (Ordanini, 2006), psychology theory refers to the study of how humans think about each other and how they relate to each other, while marketing focus on the activity, set of institutions, and processes for creating, communicating, delivering, and exchanging offerings that have value for customers, clients, partners, and society at large. 
DOI is a theory that seeks to explain how, why, and at what rate new ideas and technology spread (Rogers, 1995). Rogers argues that diffusion is the process by which an innovation is communicated over time among the participants in a social system. TRA posited that a person's positive attitude together with the individuals' thought constituted to the behavioral intention of one person. TAM is an adaption of the Theory of Reasoned Action (TRA) and was used to assess user's computer acceptance, which is measured by the intention and the influence of attitude, perceived usefulness, perceived ease of use toward the intention to use (Davis et al., 1989). The psychology theories argue that one's decision could be the influence of others on an individual's behavior (e.g. conformity, persuasion), and the formation of beliefs, attitudes, and stereotypes about other people, while marketing is a study and management of exchange relationships, which is used is used to create, keep and satisfy the customer.

Many researchers have adopted some of the theories, hybrid them together and adapted to find factors that really influence one's decision. Although findings are varies, they do contribute to some extent to the understanding of researchers, academicians and practitioners and each of them deserves an acknowledgment.

\section{Conceptual Framework}

There are many factors that lead to online shopping. Based on the theories stated earlier, three variables were chosen to explore the factors that affect online shopping in this study. These are customer satisfaction, motivation and influence from other customers.

\subsection{Customer Satisfaction}

Customer satisfaction is when products and services meet the expectation of the consumers (Bourlakis et al., 2008). It is very important that consumers are content with the products and services provided by the particular website as satisfied customers are likely to be loyal and make repetitive purchases which will increase profitability of that particular e-commerce company (Broekhuizen and Huizingh, 2009). Study by Al-Karim (2013) found that if customers satisfy with certain products that bought online from an online seller, there is a tendency that they will buy again with the same shop. In the same vein, Katawetawaraks and Wang (2011) posited that if customers are satisfy with the price and the availability of products and services, they are willing to buy online. Thus, this leads to the first hypothesis:

H1: Customer satisfaction significant positively influences online shopping.

\subsection{Motivation}

There are many reasons why people shop online. Katawetawaraks and Wang (2011) contend that online shopping allow consumers buy almost anything at any time without going to the store; they can find the same product at a lower price by comparing different websites at the same time; they sometime want to avoid pressure when having a face-to-face interaction with salespeople; and also they can avoid in store traffic jam. These are some of the motivations that lead consumer to shop online (Bagdoniene and Zemblyte, 2009).

$\mathrm{H} 2$ : Motivation significant positively influences online shopping. 


\section{Macrothink}

\subsection{Influence from Other Buyers}

A study by Grahl et al. (2014) from Mainz University demonstrated that online purchasing behavior is heavily influenced by the recommendations made by other customers. In their study with a duration of almost four weeks that involved a toy and game mail order company, the display of social network endorsements such as the Facebook 'Like' thumbs-up sign and the ' +1 ' button in Google+ resulted in a 13 percent increase in sales in the test group in comparison with a control group. Kannan and Hongshuang (2017) stated that the digital environment has a growing effect on consumer's mind and buying behaviour. In an online shopping environment, interactive decision may have an influence on aid customer decision making. Each customer is becoming more interactive, and thus online reviews customers can influence other potential buyers' behaviors (Kannan and Hongshuang, 2017).

H3: Influence from other buyers significant positively influences online shopping.

Based on the previous studies, and adapted some of the variables in the theories above, three hypothesis was then developed as in Figure 1:

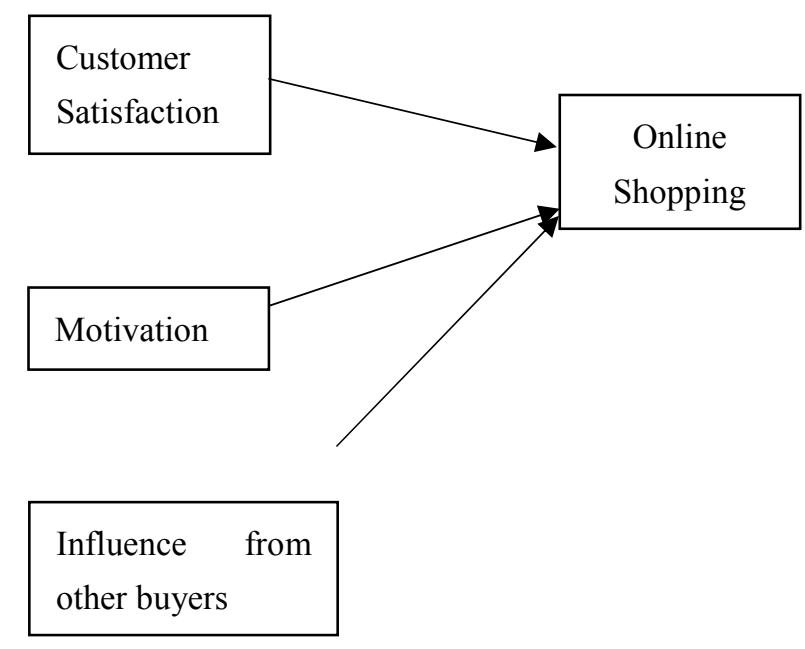

Figure 1. Conceptual framework of the study

The framework in Figure 1 is used in this study to investigate the usages and factors of online shopping among the part-time university students. The research questions are: 1) what are the extent online shopping among university students; and 2) what are the factors influencing the online shopping usages.

\section{Method}

The data for this paper is gathered through a group administered questionnaire. A questionnaire survey is a data gathering method that is utilised to collect, analyse and interpret the views of a group of people from a target population (Gratton and Jones, 2004; Leedy and Omrod, 2005). Surveys have been used in various fields of research, such as 
sociology, marketing research, politics and psychology. (Leedy and Omrod, 2005). Part-time students were chosen in this study as they represent the group of people whose time are highly occupied with working and studying. They have less time to mingle around and also to do the traditional shopping. With the hectic work life and assignments make them less socialize with other people except their colleagues. Therefore, they are likely to become convenience shoppers and may opt to shop online.

More than five hundred part-time business students who currently registered at University Kebangsaan Malaysia (UKM) were identified to be the respondents of this survey. However, only 213 students were chosen for the survey due to their attendance for the pre-registration and willingness to answer the questions. Each respondent was handed a questionnaire and asked to complete it while waiting (Patton, E. and Appelbaum, 2003) their name to be called for the registration. If the respondents were unclear about the meaning of a question, they could ask for clarification.

Once the respondents submit their questionnaire, short face-to-face interviews were conducted with respondents who are available and willingly for discussion. During this session, respondents and interviewer were freely to ask and to response to any questions. This method gathered more fruitful information for the interviewer. Only fifteen participated in the face-to-face discussions. All responses from the discussions were jotted down on a notebook for further reference and future used. Most of the time, the session with the respondents took around $20-30$ minutes. A detail of the interviews is discussed somewhere else.

\section{Results}

\subsection{Respondents'Profiles}

168 students return back the questionnaire and were found to be useable. As expected most of the respondents who return back the questionnaire have experienced online shopping either through their computers or mobile phones. Interestingly, some of the respondents have more than one phone and some of them have a dedicated phone just for online shopping. Many respondents are above twenty-five years old (more than 50\%), and as expected most of them are pursuing their Bachelor degree. One interesting finding is that most respondents in this survey that experience online shopping have a monthly household below RM4,000, which are considered B40 group of income. Part of the reasons is maybe there are searching for much cheaper items online that buying offline. Another interesting finding is that online shopping is much used by the single and divorcee person which can drive our assumption that single people may have more ample time to shop online. Although many respondents have online shopping experience, only $75 \%$ stated that they have bought online before. Some bought from a friend, some bought from retailers and most of them refer to the advertising from Facebook and Instagram which they think are very convenient way to do so. Table 1 displays the respondent characteristics. 


\section{Macrothink

Table 1. Respondents' characteristics $(\mathrm{N}=168)$

\begin{tabular}{|c|c|c|c|}
\hline Age & & Education & \\
\hline 25 and below & $12 \%$ & pursuing) & \\
\hline $26-30$ & $44 \%$ & Diploma & $8 \%$ \\
\hline $31-35$ & $32 \%$ & Bachelor & $56 \%$ \\
\hline Above 35 & $12 \%$ & Master & $26 \%$ \\
\hline Gender & & $P h D$ & $10 \%$ \\
\hline $\begin{array}{l}\text { Male } \\
\text { Female }\end{array}$ & $\begin{array}{l}25 \% \\
75 \%\end{array}$ & $\begin{array}{l}\text { Monthly household } \\
\text { income }\end{array}$ & \\
\hline & & Less RM1K & $8 \%$ \\
\hline Ethnicity & & RM1K-RM3K & $47 \%$ \\
\hline Malay & $52 \%$ & RM3001-RM4K & $27 \%$ \\
\hline Chinese & $25 \%$ & More than RM4K & $8 \%$ \\
\hline Indian and others & $15 \%$ & & \\
\hline Marital Status & & & \\
\hline Single & $40 \%$ & & \\
\hline Married & $50 \%$ & & \\
\hline Divorce & $10 \%$ & & \\
\hline
\end{tabular}

\subsection{Time Usage}

Most of the respondents $(65 \%)$ check on their online shopping for more than 10 times in a day and an accumulation of more than 4 hours a day. Surprisingly, $40 \%$ of the respondents said that they shop online more than 7 hours a day. Table 2 reports the number of hours respondents spent using online shopping per day.

Table 2. Time spent for online shopping $(\mathrm{N}=168)$

\begin{tabular}{lll}
\hline Time & Frequency & Percentage \\
\hline$<1$ hour & 15 & 8.9 \\
$1-3$ hours & 38 & 22.7 \\
$4-6$ hours & 43 & 25.6 \\
$>7$ hours & 72 & 42.8 \\
\hline
\end{tabular}

Some of the respondents shop online not only during their leisure time, but also during the class hours or working hours, which could divert their focus on their daily tasks. Most of the time, respondents have their phones with them and the tendency to access the Internet is quite high since the Internet connection is ubiquitous. Thus, the more time a student spends on online shopping, the less likely that they are focused to the work and also academic work, which may also lead to difficulties for them at the end of the day to complete their tasks 
(Hashim, 2017). These may distract their attention from the main work and also lesson, and are not able to fully understand what is going on - i.e. he or she has less time to focus their work properly and to attend to academic matters such as class work, assignments, preparation for class test, and end of the semester's examination. This may lead to both poor work and the student's lower or poor grade points (Hashim, 2017).

\subsection{Website and Social Media Usages}

Table 3 displays the percentage of respondents usually visit and buy online. Most popular marketplace is Lazada, a Southeast Asian e-commerce company founded by Rocket Internet in 2012, and owned by Alibaba Group. This is expected because Lazada is a big marketplace which offers variety of items and it is among the first of its kind in Malaysia. Although Mudah.my and Lelong.com exist before Lazada, they have been less popular. This might be due to the promotion of these websites on media and the variations of products they sell. Next after Lazada, follows by $11^{\text {th }}$ Street, Mudah.my, Shoppe and Lelong.com. Some of respondents still shop in Amazon, but many are reluctant due to the exchange rate charged.

Table 3. Respondents' online shopping group ( $\mathrm{N}=168)$

\begin{tabular}{llll}
\hline Online shopping website & Percentage & Social Media & Percentage \\
\hline Lazada & 90 & Facebook & 80 \\
$11^{\text {th }}$ Street & 70 & Instagram & 72 \\
Mudah.my & 68 & Blogs & 55 \\
Shoppe & 58 & Twitter & 45 \\
Lelong.com & 20 & WhatsApp & 20 \\
Others & 25 & Others & 20 \\
\hline
\end{tabular}

Among the social media, as expected, Facebook is the most popular. This might be because Facebook is among the first social networking sites that people get engaged to. It allows sharing of information including products and services. Due to the demand, Facebook offers commercial page which leads to a fanpage and now Facebook business. Instagram is another medium which is getting recognition among the younger generations. Instagram displays many pictures and short videos which meets the interest of these generations (Hashim, 2017). WhatsApp, although is among the densely used, it still not popular as an online shopping site. However, recently, occasionally WhatsApp users have been entertained with advertisements.

\subsection{Hypothesis Testing}

To explore the three hypotheses, the analysis used a five point Likert-type scale for measuring the relationships between the three factors and online shopping. The respondents were asked about confirmation of customers' degree of satisfaction, motivation and also influence from other buyers. This instrument had a reliability Cronbach Alpha of .71. The results, depicted in Table 4, support all hypotheses. The three factors were significantly correlated. 
Table 4. Correlation between three antecedents and online shopping

\begin{tabular}{ll}
\hline & Online shopping \\
\hline Customer satisfaction & $.423^{* *}$ \\
Motivation & $.241^{*}$ \\
Influence from other buyers & $.417^{*}$ \\
\hline
\end{tabular}

$*$ Significant at $\mathrm{p}=.05$

$* *$ Significant at $\mathrm{p}=.01$

From Table 4, consistent with other studies Al-Karim (2013) and Bagdoniene and Zemblyte (2009), we found that customer satisfaction is be the most important antecedent for online shopping. It may be also a very important antecedent for traditional marketing, but it appears to be more so for online shopping. Once customer feel satisfied with certain online seller, they will keep on buying from the same seller because the trust has been slowly built (Jamil et al., 2011; Madahi \& Sukati, 2014).

Influence from other buyers comes much closed to customer satisfaction which is 0.004 difference. Although it is the second important antecedent in this study, it seems that the respondents in this study agree that they would buy from the website that have been bought by their colleagues or other buyers. Customer would appreciated to have a testimonial and recommendation from other buyers before they proceed online purchasing. Surprisingly, some of the respondents stated that they are more comfortable to buy online from the websites or sellers that have been bought by their friends. In fact, two-third of the respondents interviewed, stated that the bought online from a recommendation websites of their friends. In this case, it could be that most respondents are mimicking actions of a larger group through local interaction and without centralized coordination (Rafaat et al., 2009). In many cases, herd behavior is a set of decisions and actions that an individual would not necessarily make on his or her own but more towards what others have benefitted it. This might be because they do not want to be cheated and afraid of fraudulent (Kannan \& Hongshuang, 2017).

Although motivation is the last important antecedent in this study, customer needs to be motivated to buy online. Some of the motivations found in this study include the ease of access of the website, the price offer and also the delivery service by the seller, which are similar to study by Topaloğlu (2012) and Yeboah and Ewur (2014).

\section{Discussion}

Electronic commerce through online shopping is growing rapidly. Based on the experience of Internet growth in the recent years, it is expected that online shopping and buying will explode in the near future and will soon become a part of people's life. Businesses and researchers as well as the government can no longer afford to ignore it, particularly to the younger generations, students in colleges and in this context part-time students. The present research is one of a very few attempts to deal with the subject and context. The discussion of antecedents in the literature is based toward traditional channels of shopping (Church and 
Oliveira, 2013) as well as the diffusion of innovations since online shopping involve the disruptive technology such as the internet. This paper contributes to this area by validating other studies but from a different context of study. Nevertheless, antecedents such as customer satisfaction, motivation, and influence from other buyer and online shopping are found to be significantly correlated. Further research should explored in more details of each of the antecedents to provide more insight value.

We discover influence from other buyer as an antecedent of online shopping is quite new and important for online shopping on the Internet. Do customers buy because of others have done so? This could also be further research to explore if herding behavior contribute to online buying. Potential customers need to get feedback on certain online seller in order to proceed to buy the item. Hence, online marketplace such Lazada, Shoppe and others need to make aware of this. The other two antecedents which are also applicable for traditional marketing seem to be relevant to online shopping. Since electronic commerce in Malaysia is still quite new and on the growing stage of product life cycle, it is difficult to conduct a sizeable scale of survey. Future researches may be conducted in two areas. First, the researchers need to include all types of consumers and lines of businesses for generalizing of the research model on online shopping. Second, samples of this study should be conducted on a larger scale and with a greater variety.

\section{Limitation}

Similar to most research, this paper has limitations that point to further opportunities. The author focuses on 168 part-time business students in only one university. Building on this research, there are opportunities for further work. The present research could serve as a starting point for more detailed studies. Additional studies on other tertiary institutions should provide further insights into the impact of online shopping on the performance of tertiary students in Malaysia. This research can be utilised to investigate the use of online shopping not only at university, but also at school, home, workplace, and various other settings, and for a variety of different audiences such as teenagers, young adults, the elderly, or families and should also focus on a bigger sample. For future research, it may be more helpful to examine how not only student's but also customers' psychological state and other buyers influences the motivations to perform online shopping.

\section{Acknowledgments}

A part of this project is funded by Universiti Kebangsaan Malaysia under grant titled Developing a Framework of Social Media in Entrepreneurship Performance and Sustainability.

\section{References}

Al-Karim, R. (2013). Customer Satisfaction in Online Shopping: A Study into the Reasons for Motivations and Inhibitions. Journal of Business and Management, 11(6), 13-20.

Amit, K. S., \& Sailo, M. (2013). Consumer Behavior in Online Shopping: A Study of Aizawl. International Journal of Business \& Management Research (IJBMR), 1(2), 45-39. 
Azjen, I. (1991). The Theory of Planned Behavior. Organizational Behavior and Human Decision Processes, 50, 179-211. https://doi.org/10.1016/0749-5978(91)90020-T

Bagdoniene, L., \& Zemblyte, J. (2009). Online Shopping Motivation Factors and Their Effect on Lithuanian Consumers. Economics and Management, 11, 367-374.

Bianchi, C., \& Andrews, L. (2012). Risk, Trust, and Consumer Online Purchasing Behaviour: A Chilean Perspective. International Marketing Review, 29, 253-275. https://doi.org/10.1108/02651331211229750

Bouhnik, D., \& Deshen, M. (2014). Online Shopping Goes to School: Mobile Instant Messaging between Teachers and Students. Journal of Information Technology Education Research, 13, 217-231. https://doi.org/10.28945/2051

Bourlakis, M., Papagiannidis, S., \& Fox, H. (2008). E-consumer Behaviour: Past, Present and Future Trajectories of An Evolving Retail Revolution. International Journal of E-Business Research, 4(3), 64-67. https://doi.org/10.4018/jebr.2008070104

Broekhuizen, T., \& Huizingh, E. (2009). Online Purchase Determinants: Is Their Effect Moderated By Direct Experience? Management Research News, 32(5), 440-457. https://doi.org/10.1108/01409170910952949

Chang, M. K., Cheung, W., \& Lai, V. S. (2005). Literature Derived Reference Models For The Adoption of Online Shopping. Information \& Management, 42, 543-559. https://doi.org/10.1016/S0378-7206(04)00051-5

Chew, J. (2018). History of E-commerce in Malaysia. Borneo Post Online. Retrieved from http://www.theborneopost.com/2018/07/15/history-of-ecommerce-in-malaysia/

Chuang, T. T., Nakatani, K., Chen, J. C. H., \& Huang, I. L. (2007). Examining the Impact of Organisational and Owner's Characteristics on the Extent of E-commerce Adoption in SMEs. International Journal Business and Systems Research, 1(1), 61-80. https://doi.org/10.1504/IJBSR.2007.014770

Church, K., \& Oliveira, R. D. (2013). What's up with Online shopping?: Comparing Mobile Instant Messaging Behaviors With Traditional SMS, MobileHCI '13 Proceedings of the 15th International Conference On Human-Computer Interaction With Mobile Devices And Services, pp. 352-361.

Criteo. (2016). Report on Browsing \& Buying Behaviour 2016. Retrieved from https://www.criteo.com/wp-content/uploads/2018/01/Browsing-Buying-Behaviour-2016-UK. $\mathrm{pdf}$

Daniel, E., Wilson, H., \& Myers, A. (2003). Adoption of E-commerce by SMEs in the UK. International Small Business Journal, 20(3), 253-270. https://doi.org/10.1177/0266242602203002

Davis, F. D. (1989). Perceived Usefulness, Perceived Ease of Use, and User Acceptance of Information Technology. MIS Quarterly, 13(3), 319-340. https://doi.org/10.2307/249008 


\section{Al Macrothink}

Business and Management Horizons

ISSN 2326-0297

2018, Vol. 6, No. 2

Debroff, S. (2017). Shoppers Delight: 6 Ways Today’s Online Culture Impacts Retail Sales.

Retrieved from https://www.business.com/articles/shoppers-delight-6-ways-todays-online-culture-impacts-ret ail-sales/

Grahl, J., Rothlauf, F., \& Hinz, O. (2014). The Impact of User-Generated Content on Sales: A Randomized Field Experiment. Working Paper Series, Technische Universität Darmstadt.

Gratton, C., \& Jones, S. (2004). Research Methods for Sports Studies. London: Routledge.

Harn, A. C. P., Khatibi, A., \& Ismail, H. (2006). E-Commerce: A Study on Online Shopping in Malaysia. Journal of Social Science, 13(3), 231-242.

Hashim, N. A. (2017). Embracing the Instagram Waves - The New Business Episode to the Potential Entrepreneurs. Journal of Entrepreneurship and Business Innovation, 4(2), 13-29. https://doi.org/10.5296/jebi.v4i2.12092

Hashim, N. A., Abdullah, N., \& Makhbul, Z. M. (2013). Website for Online Selling Implementation among SMEs in Malaysia. IADIS International Journal, 11(3), 76-88.

Hashim, N. A., Mohd Nor, S., \& Janor, H. (2016). Riding the Social Commerce Waves among Malaysian Entrepreneurs. Geografia: Malaysian Journal of Society and Space, 12, 83-94.

Jamil, N. A., \& Mat, N. K. (2011). To Investigate The Drivers of Online Purchasing Behavioral in Malaysia Based on the Theory of Planned Behavior (TPB): A Structural Equation Modeling (SEM) Approach. International Conference on Management, pp. 453-460.

Kannan, P. K., \& Hongshuang, A. L. (2017). Digital marketing: A Framework, Review and Research Agenda. International Journal of Research in Marketing, 34(1), 22-45. https://doi.org/10.1016/j.ijresmar.2016.11.006

Katawetawaraks, C., \& Wang, C.L. (2011). Online Shopper Behavior: Influences of Online Shopping Decision. Asian Journal of Business Research, 1(2), 66-74. https://doi.org/10.14707/ajbr.110012

Leedy, P. D., \& Omrod, J. E. (2005). Practical Research: Planning and Design (8th ed.). NJ: Prentice Hall.

Madahi, A., \& Sukati, S. (2014). Consumers Attitudes towards Internet and Brick and Mortar Store Channels Switching Behavior. Journal of the Faculty of Economics and Administrative Sciences, 4(2), 137-166.

Marketing Dive. (2018). Gen Z more likely to visit shopping malls, fast-food restaurants, study finds. Retrieved from https://www.marketingdive.com/news/gen-z-more-likely-to-visit-shopping-malls-fast-food-re staurants-study-fin/530218/

Narges, D., Laily, H. P., Haron S. A., Sidin, S. M., \& Ali Khatibi, A. (2009). Factors Affecting 


\section{Macrothink}

Business and Management Horizons

ISSN 2326-0297

2018, Vol. 6, No. 2

Students' Attitude toward Online Shopping. African Journal of Business Management, 3(5), 200-209.

Ordanini, A. (2006). Information Technology and Small Businesses - Antecedents and Consequences of Technology Adoption. Cheltenham: Edward Elgar.

Patton, E., \& Appelbaum. (2003). The Case for Case Studies in Management Research. Management Research News, 26, 60-62. https://doi.org/10.1108/01409170310783484

Raafat, R. M., Chater, N., \& Frith, C. (2009). Herding in Humans, Trends in Cognitive Sciences, pp. 420-428. https://doi.org/10.1016/j.tics.2009.08.002

Rogers, E. M. (1995). Diffusion of Innovations (4th ed.). Free Press, New York.

Ryan, M. (2017). How The Younger Generation Changed E-commerce For Everyone, Retrieved from https://www.debtroundup.com/younger-generation-changed-ecommerce/\#comments

Shambare, R. (2014). The Adoption of Online Shopping: Breaking the Vicious Cycle of Technological Poverty in South Africa. Journal of Economics and Behavioral Studies, 6(7), 542-550.

Statista (2018). Retail E-Commerce Sales Worldwide from 2014 to 2021. Retrieved from https://www.statista.com/statistics/379046/worldwide-retail-e-commerce-sales/

Statista. (2018). Malaysia Online Shoppers by Age. Retrieved from https://www.statista.com/statistics/878419/malaysia-online-shoppers-by-age/

Topaloğlu, C. (2012). Consumer Motivation and Concern Factors For Online Shopping In Turkey. Asian Academy of Management Journal, 17(2), 1-19.

Yeboah, J., \& Ewur, G. D. (2014). The Impact Of Online Shopping Usage On Students' Performance In Tertiary Institutions In Ghana. Journal of Education and Practice, 5(6), 157-164.

Yin, J. L., Abdullah, O., Shahrul, N. S., Abdul Rahim, R., \& Safizal, A. (2016). Factors Influencing Online Shopping Behaviour: The Mediating Role of Purchase Intention. Procedia Economics and Finance, 35, 401-410. https://doi.org/10.1016/S2212-5671(16)00050-2

Zendehdel, M., Laily, H. P., \& Syuhaily, O. (2015). Students' Online Purchasing Behavior in Malaysia: Understanding Online Shopping Attitude. Cogent Business \& Management Journal, 2(1), 1-13. https://doi.org/10.1080/23311975.2015.1078428

Zwass, V. (1996). Electronic Commerce: Structures and Issues. International Journal of Electronic Commerce, 1(1), 1-23. https://doi.org/10.1080/10864415.2018.1396106 


\section{Macrothink}

\section{Copyrights}

Copyright for this article is retained by the author(s), with first publication rights granted to the journal.

This is an open-access article distributed under the terms and conditions of the Creative Commons Attribution license (http://creativecommons.org/licenses/by/4.0/). 